\title{
Evidence for split foci of attention in a priming paradigm
}

\author{
INGRID SCHARLAU \\ Bielefeld University, Bielefeld, Germany
}

\begin{abstract}
Most models of visuospatial attention include the notion that attention is dedicated to a single location in space. However, several researchers have found evidence that under appropriate circumstances, attention may be allocated to noncontiguous locations (e.g., Awh \& Pashler, 2000; Bichot, Cave, \& Pashler, 1999; Kramer \& Hahn, 1995). In the present experiments, the spatial distribution of attention was assessed by a novel method, perceptual latency priming: the latency benefit of an attended visual stimulus, as compared with a nonattended stimulus. Experiment 1 assessed whether observers are able to attend to two nonadjacent regions or a region of variable size. Experiment 2 tested whether, when two distant locations are attended to, the region between them is necessarily also in the focus of attention. Two further experiments controlled for objections against the method used and replicated the main results of the first two experiments. The experiments showed a robust attentional priming effect at two noncontiguous locations of the visual field, simultaneous with little or no priming of the intervening location.
\end{abstract}

It is a traditional axiom that human attention can be dedicated to only one object at a time. Although humans may perform two actions at the same time, often without a loss in quality, it is much more difficult, if not impossible, to attend to two locations simultaneously. Such a view of attention is reflected, for example, in the spotlight metaphor for the beam of attention. In trying to support this notion, Posner, Snyder, and Davidson (1980) investigated whether attention could be allocated to different locations of the visual field. They compared response time facilitation for targets appearing at a primary and a secondary cue's locations. There was no facilitation for the secondary cue's location unless it was adjacent to the primary cue. This was regarded as evidence for a single attentional focus. However, their design may not have met some important preconditions for splitting attention into noncontiguous regions, such as a high incentive to process both cues. In their study, the secondary prime was valid only in a quarter of the trials. Thus, there was only a marginal motivation to attend to the secondary cue. Further studies in which evidence supported unitary attention also employed cues with a validity of less than $50 \%$ (C. W. Eriksen \& Yeh, 1985; McCormick \& Klein, 1990). By contrast, research in which validity was more than $50 \%$ typically revealed evidence for the allocation of

The research reported in this article was supported by DFG Grant NE 366/5-3 to Odmar Neumann. I thank Ulrich Ansorge, Gernot Horstmann, and Ellen Brinkmeier for stimulating discussions and four anonymous reviewers for their very valuable comments on an earlier draft of the manuscript. Parts of the data were presented at the Munich Visual Search Symposium, June 6-10, 2003, Holzhausen, Germany. Correspondence should be sent to I. Scharlau, Department of Psychology, Bielefeld University, P. O. Box 1001 31, D-33501 Bielefeld, Germany (e-mail: ingrid.scharlau@uni-bielefeld.de). attention to both cues' locations (Awh \& Pashler, 2000; Hahn \& Kramer, 1998; Kramer \& Hahn, 1995). Furthermore, the necessity to suppress distractor processing seems to be a favorable precondition for splitting attention (Awh \& Pashler, 2000; see also Pan \& Eriksen, 1993). These findings may explain why, for instance, Heinze et al. (1994) and Pan and Eriksen found no evidence for split attention. Several later studies have indeed demonstrated that it is possible to attend to two noncontiguous regions of the visual field (Awh \& Pashler, 2000; Bichot et al., 1999; Castiello \& Umiltà, 1992; Hahn \& Kramer, 1998; Kramer \& Hahn, 1995; Müller \& Findlay, 1987).

In the following, I propose to study the possibility of split attentional foci with an alternative, novel method. I first will describe this method-prior entry, or perceptual latency priming - and then will show how it may be used to investigate the possibility of attending to noncontiguous regions.

Most models of visuospatial attention agree that one of the functions of attention is to enhance the processing of the attended information at the expense of other, nonattended sources of information (e.g., Posner, 1980; Treisman, 1988). Attention decreases response latencies toward the attended targets (e.g., C. W. Eriksen \& Hoffman, 1972; Posner, 1980), ameliorates performance accuracy (e.g., Müller \& Rabbitt, 1989; Nakayama \& Mackeben, 1989), and decreases the perceptual latency of the attended target. The latter phenomenon, termed prior entry (Titchener, 1908), may be employed as a means for studying the deployment and spatial distribution of attention.

In prior entry research, observers are cued to attend to a certain location. Two targets appear in the visual field, one at the attended location and the other one at a nonattended location. The observers judge their temporal order. Typically, the attended target is perceived as ap- 
pearing earlier than the unattended one. This finding indicates that its perceptual latency is decreased. By varying temporal and spatial parameters of the stimulus sequences, the distribution of attention over the visual field can be investigated in detail.

Prior entry can be elicited endogenously by instructing the observers to attend to a certain location or $e x$ ogenously via attentional capture by a peripherally presented visual cue that captures attention. Although prior entry has been found with both methods (e.g., Shore, Spence, \& Klein, 2001; Stelmach \& Herdman, 1991; see also Hikosaka, Miyauchi, \& Shimojo, 1993a, 1993b), exogenous cuing has some important advantages. Several studies have shown that endogenously manipulated attentional effects may substantially change with judgment criterion (Frey, 1990; Shore et al., 2001) or may vanish if the number of judgment alternatives is increased (Jaśkowski, 1993). By contrast, exogenously mediated prior entry is only marginally affected by changing the judgment criterion (i.e., asking which of the two targets was the first one or which was the second one; Scharlau, 2003, 2004; Shore et al., 2001) or the number of alternatives (Scharlau, 2003, 2004).

Perceptual latency priming is a special case of exogenously mediated prior entry in which the spatial cue (termed the prime) is masked and, thus, invisible. Since the target and the cue typically appear at the same location, the target may be used to impair the cue's visibility by metacontrast masking ${ }^{1}$ thus allowing one to study the effects that a masked prime exerts on information processing (the priming paradigm; see Klotz \& Neumann, 1999). Detection of the masked cue and, especially, discrimination of its features are severely reduced (for data in prior entry paradigms, see Scharlau \& Ansorge, 2003, and Scharlau \& Neumann, 2003a; for data in response time paradigms, see, e.g., Klotz \& Neumann, 1999). However, its ability to attract attention prevails (attentional priming; Jaśkowski, van der Lubbe, Schlotterbeck, \& Verleger, 2002; McCormick, 1997; Scharlau \& Neumann, 2003a, 2003b).

Metacontrast masking requires that the prime and the masking target be relatively similar and presented in close temporal and spatial proximity (Breitmeyer, 1984; although see Enns \& Di Lollo, 1997). Therefore, perceptual latency priming could be an artifact of amalgamating the prime and the target into a compound stimulus. $\mathrm{Ob}-$ servers might judge an inferred temporal center or a perceptual center (e.g., Scott, 1998) instead of the target's onset. Earlier studies have presented evidence against this alternative explanation. (1) A perceptual center that lies between the first onset and the last offset of a sequence should be influenced by target duration. However, perceptual latency priming is independent of target duration (Scharlau \& Neumann, 2003b). (2) Also, a perceptual center should be independent of whether the prime leads or trails the target. By contrast, only leading masked primes facilitate perceptual latency, as is predicted by an attentional account of perceptual latency priming (Scharlau, 2002). (3) Most important, observers are able to correctly date the prime and, simultaneously, misperceive the target's onset. Thus, temporal integration of the prime and the target is not a necessary precondition for perceptual latency priming. When primetarget and target-target temporal order judgments (TOJs) are intermixed, the prime's onset is perceived correctly and the primed target's onset is simultaneously facilitated by the prime (Scharlau, 2002). This finding rules out the possibility that observers solve the TOJ task by waiting for the first onset, catching the prime's onset in some proportion of the trials and the target's onset in another proportion. In accordance with other studies on perceptual latency (e.g., Hikosaka et al., 1993a, 1993b; Shore et al., 2001; Spence, Shore, \& Klein, 2001; Stelmach, Campsall, \& Herdman, 1997; Stelmach \& Herdman, 1991; Zackon, Casson, Zafar, Stelmach, \& Racette, 1999), these findings support an attentional account of perceptual latency priming, according to which perceptual latency priming is due to the facilitative influence of attention. ${ }^{2}$

In the perceptual latency priming paradigm, the possibility of split attentional foci can be studied by using a pair of primes and assessing in which region or regions attention-mediated facilitation is present. According to the split attention hypothesis, it should be possible to attend to two noncontiguous locations and achieve benefits at both locations. The experiments presented below tested this prediction.

The TOJ task measures relative facilitation for two stimuli or locations. Finding perceptual latency priming warrants the conclusion that the primed stimulus is facilitated more than the unprimed one. This is an important feature of the perceptual latency priming paradigm: It directly compares relative facilitation at two locations, an attended and an unattended one or, alternatively, two attended ones, or even at two locations with different amounts of attention.

Perceptual latency priming by a single prime, as assessed in several previous studies (Neumann, Esselmann, \& Klotz, 1993; Scharlau, 2002, 2004; Scharlau \& Ansorge, 2003; Scharlau \& Neumann, 2003a, 2003b; Steglich \& Neumann, 2000), may be in accordance with split attentional foci, but it also accords with several alternative models of the spatial distribution of attention, such as gradient theories (Downing, 1988; Downing \& Pinker, 1985; Hikosaka et al., 1993a; Hughes \& Zimba, 1985; LaBerge, 1983; LaBerge \& Brown, 1989), that suppose that attention is organized in a gradient fashion around the attended location - that is, decreasing with distance from the focus of attention. It also agrees with a spotlight theory of attention (Broadbent, 1982; Posner, 1980; Posner et al., 1980; Shulman, Remington, \& McLean, 1979; Tsal, 1983), according to which an area of defined size, possibly of less than $1^{\circ}$ of visual angle, is attended to, and with a zoom lens model (B. A. Eriksen \& C. W. Eriksen, 1974; C. W. Eriksen \& Hoffman, 1972; C. W. Eriksen \& St. James, 1986; C. W. Eriksen \& Yeh, 1985), according to which the width of the focus can be ad- 
justed to the task demands. The size of the zoom lens is typically inversely related to the resolution of attentionthat is, the amount of attentional facilitation (e.g., Castiello \& Umiltà, 1992; C. W. Eriksen \& St. James, 1986; Handy, Kingstone, \& Mangun, 1996; Turatto et al., 2000).

\section{OVERVIEW}

By means of perceptual latency priming, the experiments tested whether observers would be able to attend simultaneously to two noncontiguous regions of the visual field. To achieve this, two primes were presented simultaneously in advance of two asynchronously presented targets. One prime appeared at the target's location, and the other one at a location that would later be occupied by a distractor element. If the observers oriented toward only one of the primes, due to a narrow or unadjustable focus (a spotlight), the amount of perceptual latency priming would be reduced, as compared with a single-prime condition. This was expected because the observers would randomly attend to one of the primes and only one of them preceded the critical target that contributed to perceptual latency priming. Thus, in half of the trials, on average, the target received no benefits and perceptual latency priming would be diminished. By contrast, the split attention hypothesis predicts that a double prime elicits the same amount of attentional facilitation as a single prime. The predictions of the zoom lens model are indistinct. If observers zoom their attention to a larger region in the double-prime than in the single-prime condition and if the size of the focus and its resolution are inversely related, facilitation by a double prime should be weaker than facilitation by a single prime. However, other zoom modes (e.g., equally large foci in the two conditions) are conceivable.

The zoom lens model and the split foci hypothesis provide, however, clearly different predictions about what happens if stimuli fall into an area in between the two noncontiguous primed regions. According to the zoom lens model, this region must also be attended to. Consequently, the latency of a stimulus appearing in between the two primed locations should be facilitated. By contrast, the hypothesis of split attentional foci does not expect facilitation for this area. Intermediate regions that lie in between the attentional foci will not achieve attentional benefits.

Experiments 1 and 2 answer the main questions of the present article. Experiment 1 addressed the question of whether observers are able to pay attention to two locations without a loss in facilitation for each of them and, thus, was intended to decide between the spotlight model and the split attention or zoom lens hypothesis. Experiment 2 tested whether attending to two locations implies attending to the space in between them and, thus, served to decide between the zoom lens and the split attention hypothesis. As a control, Experiments 3 and 4 tested whether perceptual latency priming is due to confusing the prime and the masking target.

\section{EXPERIMENT 1}

Experiment 1 tested whether attention is restricted to the location of one prime - that is, a single narrow regionas would be expected on the basis of the spotlight model. If attention is oriented in a spotlight fashion, a double prime should elicit fewer benefits than a single prime.

A further test of whether observers attend to only one or both of the primes is a comparison between the following two conditions. In what may be called a neutral condition, the second prime precedes the second target stimulus. If both prime locations are attended to, both targets will be facilitated, and relative facilitation for any of them disappears. No perceptual latency priming would be expected in this neutral case. By contrast, if the second prime precedes a distractor element, relative facilitation for the primed target, in comparison with the unprimed target, should persist.

Experiment 1 included four priming conditions: (1) without a prime (termed unprimed), (2) a single prime preceding the comparison target (single), (3) a double prime preceding both targets (double/neutral), and (4) a double prime preceding one target and the distractor (double/ valid). Two critical comparisons directly test the spotlight model: first, the comparison between the singleprime condition and the double/valid condition, and second, the comparison between the double/neutral and the double/valid condition. The comparison between any primed and the unprimed conditions proves perceptual latency priming. The single-prime condition serves as a baseline of the maximal possible perceptual latency benefit under the conditions employed, with which the effect in the double-prime conditions can be compared.

\section{Method}

Participants. Eighteen paid volunteers (12 females; mean age, 24.0 years) participated in one session of $30 \mathrm{~min}$. In this as in the following experiments, all the participants had normal or correctedto-normal vision, reported no color vision deficits, and received $€ 3$.

Apparatus. The stimuli were presented on a dark gray background $\left(13 \mathrm{~cd} / \mathrm{m}^{2}\right)$ on a $17-$ in. color monitor with a resolution of $640 \times 480$ pixels and a vertical frequency of $60 \mathrm{~Hz}$. Red, yellow, and blue stimuli were used. The participants responded by pressing either the left or the right button of a mouse, using the dominant hand. Viewing distance was fixed at $60 \mathrm{~cm}$ by a chinrest.

Stimuli. In each trial, three highly visible rings $1.9^{\circ}$ in diameter were presented, one of them a distractor and two of them targets. The targets were relevant for the task and had to be compared with respect to their relative onsets. One of the stimuli was red, one yellow, and one blue. The stimuli appeared on an imaginary circle, centered around fixation, with a radius of $5.7^{\circ}$. There were six possible stimulus positions, three of which were occupied in each trial (see Figure 1 for possible spatial arrangements). These three positions formed an imaginary triangle (edge length, $9.6^{\circ}$ ).

In addition to these three stimuli, a masked prime was presented in three quarters of the trials. The prime was a smaller replica of the target ring, which fitted exactly into its inner contour $\left(1.4^{\circ}\right.$ in diameter). In one quarter of the trials, a single prime preceded one of the targets. A double/valid prime, which was presented in another quarter of the trials, consisted of a prime pair that preceded the comparison target and the distractor. A double/neutral prime pair 

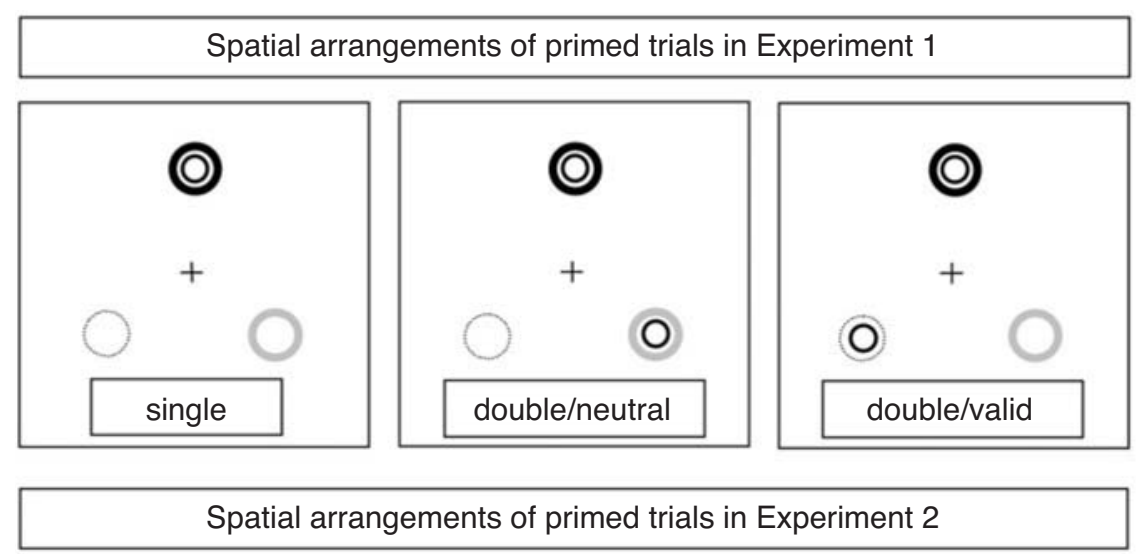
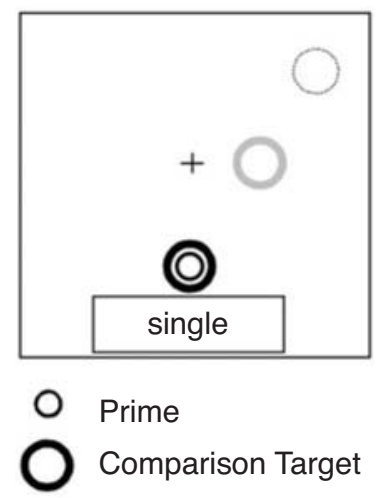
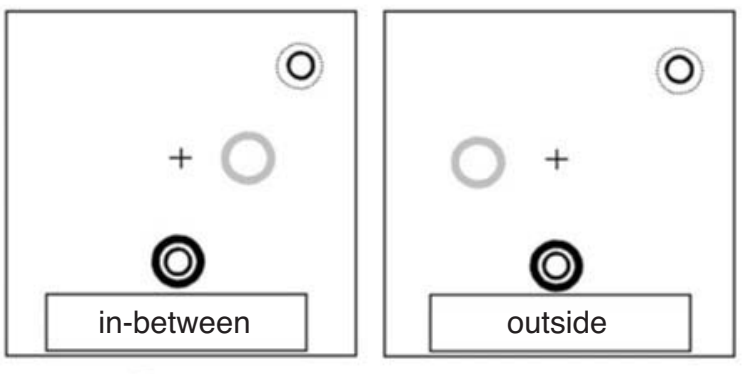

Standard Target

Distractor

Figure 1. Examples of spatial arrangements of the stimuli in Experiments 1 (top) and 2 (bottom). Colors are given by shades and line width (note that all the stimuli, except for the prime, had exactly the same size and shape). Stimuli are not drawn to scale, and temporal succession is also negotiated (note that the prime was always offset before the primed target's onset).

occupied the locations of both targets. The prime had the same color as the primed target, as defined by single-prime trials. According to psychophysical terminology, the targets will be denoted as the comparison target and the standard target, the comparison target being the primed target and the standard target being the unprimed target (except for the double/neutral condition, in which both targets were primed).

Stimulus onset asynchronies between the two targets (target SOAs) were $-48 \mathrm{msec},-16 \mathrm{msec},+16 \mathrm{msec}$, and $+48 \mathrm{msec}$ ( $\mathrm{see}$ Figure 2 for a sample trial). Negative numbers denote that the comparison target preceded the standard target. (In unprimed trials, the assignment of negative and positive SOA values was made randomly while realizing all other variables equally often.) Duration of the prime was $16 \mathrm{msec}$. The targets and the distractors were presented without offset. The positions of the targets and the distractors were balanced, and each of the two target colors was primed equally often. There were 16 conditions ( 4 target SOAs $\times 4$ priming conditions [no prime, single, double/valid, or double/neutral]). Each condition was presented 24 times in random order with the method of constant stimuli.

Procedure. There were six possible combinations of the three colors into the distractor and the two target categories. Three participants each were assigned randomly to a category. During the experiment, the participants sat in front of the monitor in a dimly lit room. The center of the monitor was marked by a small light gray square $\left(1^{\circ} \times 1^{\circ}\right)$, which remained visible throughout the experiment and had to be fixated throughout each trial. The participants were instructed to judge the temporal order of the two targets while ignoring the distractor. They indicated their judgments by pressing the left or the right button of a mouse. For example, the participants with yellow distractors, red as one target, and blue as the other one, had to press the left button if they saw the red target in advance of the blue target and the right button if the blue target was perceived to lead the red target. The instructions emphasized accuracy, and there was no time pressure.

The task was practiced in a warm-up session with 16 trials without primes. In the experimental session, a break was initiated every 32 trials.

\section{Results}

For each participant and priming condition, the frequency of the standard target first judgment was calculated for the different target SOAs, resulting in typical sigmoid psychometric distributions (see Figure 3). However, the distributions do not approach the asymptotes of 0 and 1, which shows that the target SOAs used in the experiment provide rather difficult conditions for the TOJ. In psychometric distributions, perceptual latency priming is visible in a horizontal shift of the distribution that indicates a change in perception of order. Logit analysis (Finney, 1971) was used to estimate two independent psychophysical parameters of the distribution, its center 

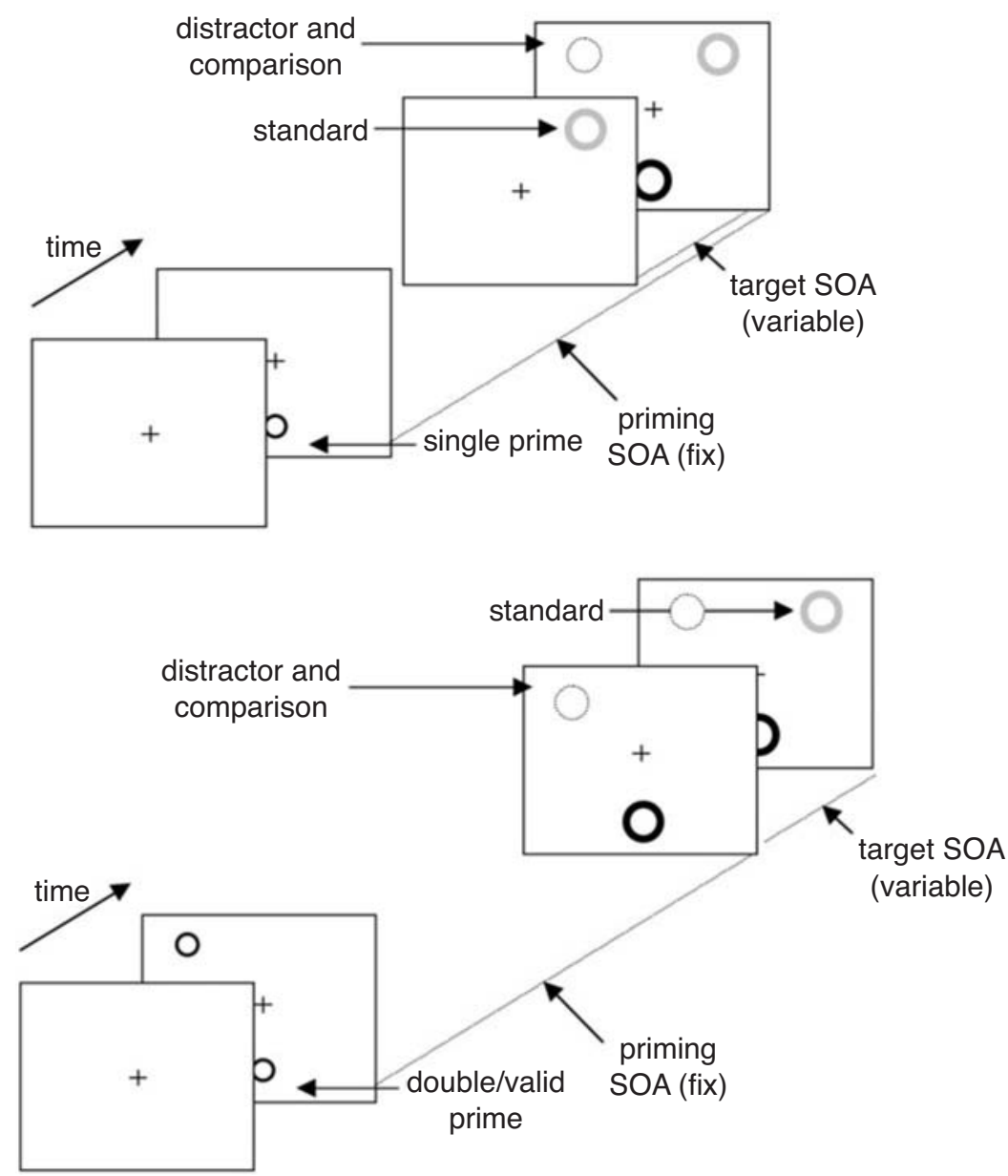

Figure 2. Succession of events for two sample trials in Experiment 1. The stimuli are not drawn to scale. Also, durations are not exact. Top: example with a single prime and a positive target stimulus onset asynchrony (SOA). Bottom: example with a double/ valid prime and a negative target SOA.

and its slope. The center is the target SOA at which the two judgment frequencies are equiprobable - that is, the point of subjective simultaneity (PSS, psychophysical threshold). Slope or discrimination accuracy is assessed by the difference limen (DL, the mean slope within the two inner quartiles of the distribution). If appropriate, degrees of freedom in the analyses of variance (ANOVAs) were corrected by the Greenhouse-Geisser coefficient $\varepsilon$, and $\alpha$ was adjusted accordingly (Hays, 1988).

One participant was not able to discriminate temporal order (DL $>1,000 \mathrm{msec})$. Her data were not included in the subsequent analysis.

Figure 3 (top) gives the judgment frequencies averaged over participants. Perceptual latency priming is obvious in two priming conditions in which the psychometric distributions are horizontally shifted, the single-prime condition and the double/valid condition. Apparently a double/neutral prime does not lead to a horizontal shift.

This picture is confirmed by statistical analysis: A one-way ANOVA of PSS revealed a main effect of prim- ing $[F(3,48)=8.16, p<.01]$. The effect size $f$ was .69 , which is defined as a large effect (Cohen, 1977). Mean PSS was $0 \mathrm{msec}$ in unprimed trials, $8 \mathrm{msec}$ with a double/ neutral prime, $39 \mathrm{msec}$ with a single prime, and $34 \mathrm{msec}$ with a double/valid prime.

If observers are able to pay attention to two locations or adjust the size of their attentional focus without a loss in attentional benefits for each position with a focus, priming effects should be identical with a double/valid and a single prime. Planned comparisons revealed that the single-prime and the double/valid conditions did not differ $(t<1)$, whereas double/neutral and double/valid conditions led to different PSSs $[t(16)=2.45, p<.05]$. Perceptual latency priming was $39 \mathrm{msec}$ with a single prime and $34 \mathrm{msec}$ with a double/valid prime (perceptual latency priming values are given in Figure 4). The small effect of $8 \mathrm{msec}$ in the double/neutral condition did not differ from the unprimed baseline.

DL did not differ with priming and was $43 \mathrm{msec}$ on average $(F<1)$. 

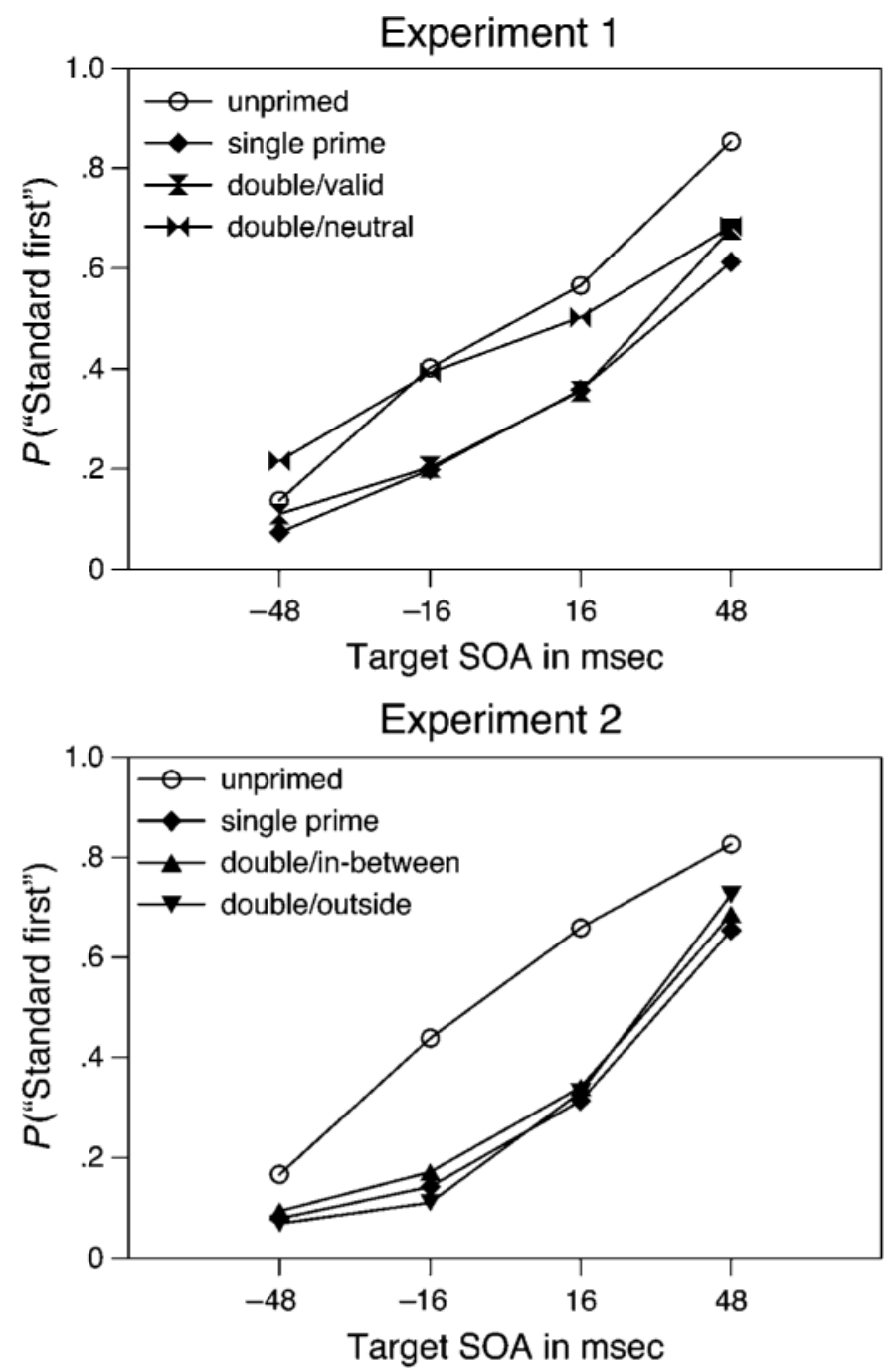

Figure 3. Psychometric distributions of the two main experiments, Experiment 1 (top) and Experiment 2 (bottom). Perceptual latency priming is evident in a horizontal shift to the right, the size of the shift indicating the amount of attentional facilitation.

\section{Discussion}

The results of Experiment 1 are in accordance with split attentional foci or a single focus of adjustable size: Observers were able to attend either to two noncontiguous regions without a loss in facilitation for either of the two locations or to a very broad region (at least $10^{\circ}$ ), again without a loss in facilitation. Relative latency benefits were statistically the same (and numerically differed by only $5 \mathrm{msec}$ ) if attention was shifted toward a single location and if it was shifted to two locations, one of which was irrelevant for the TOJ. That is, relative facilitation was independent of whether the observers attended to an additional, irrelevant location. In addition, discrimination performance (DL) was not impaired by the second focus. Thus, the present finding fulfills a strict criterion of split attentional foci-namely, that the additional focus has no detrimental influence on the benefits at the other location (Hahn \& Kramer, 1998; Kramer $\&$ Hahn, 1995). The results are in line with those of earlier studies that also used double cues and showed evidence for splitting attention between the cues' locations with tasks that were different from the present one (e.g., a match/mismatch task in Hahn \& Kramer, 1998, and a partial report in Awh \& Pashler, 2000).

The notion of split foci is also in accordance with the nonsignificant amount of perceptual latency priming in the double/neutral condition: The relative benefit of the primed target was very much reduced and did not differ from zero if the second location later contained the standard targetthat is, if both targets appeared at attended locations. 


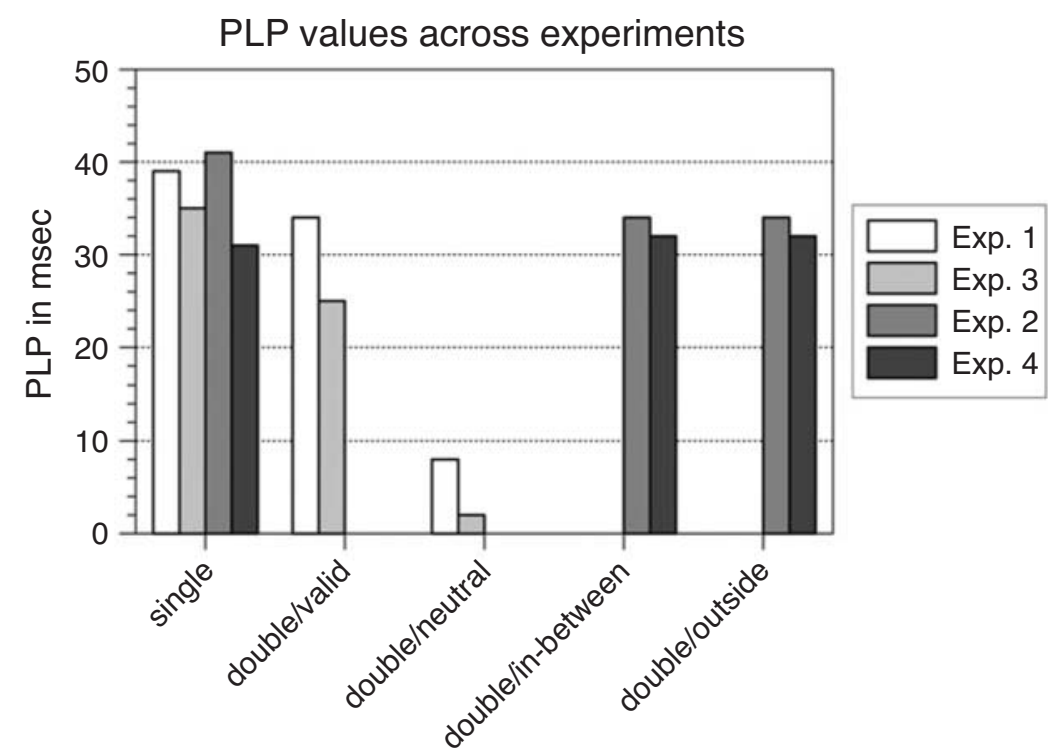

Figure 4. Perceptual latency priming (PLP) in the different priming conditions of the four experiments.

In sum, the spotlight model is incompatible with the present findings, since it predicts diminished facilitation with two possible regions of attention. Note that the present findings may have also been predicted on the basis of the zoom lens model. However, this holds only if the size of the attended region and the amount of relative facilitation for each location are not inversely related, as some researchers have assumed (e.g., Castiello \& Umiltà, 1990, 1992; C. W. Eriksen \& St. James, 1986; Handy et al., 1996; Turatto et al., 2000). The aim of Experiment 2 was to decide between the zoom lens and split foci models.

\section{EXPERIMENT 2}

In Experiment 2, the zoom lens and the split foci explanations were investigated jointly. In Experiment 2, the critical comparison was between two conditions with a double/neutral prime. In one of the conditions, the standard target was presented spatially in between the two primes (the in-between condition) - that is, within the region possibly focused by a zoom lens. If the zoom lens model is correct, the standard target would profit from attention, and perceptual latency priming should be reduced (remember that perceptual latency priming is the relative amount by which an attended target is facilitated, as compared with an unattended or a less attended target). Two possible outcomes would be in accord with the zoom lens model: no perceptual latency priming (if the standard target was facilitated as much as the comparison target) and reversed perceptual latency priming (if the standard target, which is located in the center of the attended region, received more facilitation than the comparison target, which is closer to the edge of the attended region).
In the other condition (outside), the standard target was equally distant from the comparison target, but at its other side. This location lay outside the focus of attention. Finding that facilitation is larger in the outside condition than in the in-between condition would support the zoom lens model. Finding an equal amount of facilitation would indicate split attentional foci, since obviously, the region in between the two primes was not attended to. Thus, the critical comparison is between the in-between and the outside conditions. The split attention hypothesis further requires that priming be equal in the single-prime and the in-between trials, as well as in the single-prime and the outside trials.

\section{Method}

Participants. Eighteen paid volunteers (10 females; mean age, 24.8 years) took part in one session of $30 \mathrm{~min}$.

Apparatus and Procedure. The apparatus and procedure did not differ from those in Experiment 1.

Stimuli. The stimuli did not differ from those in Experiment 1, with the following exceptions. There were four priming conditions, one of them unprimed and another one with a single prime, as defined above (Experiment 1). In the other two conditions, a double prime preceded the comparison target and the distractor. These conditions differed only in the location of the standard target. It was presented either between the two primes (the in-between condition) or outside this area in equal distance from the comparison target (the outside condition; Figure 1 exemplifies these conditions).

Furthermore, eccentricity was changed. Testing the zoom lens model straightforwardly required that the standard target be presented exactly in between the double primes. To that end, the eccentricity of the primes, the distractor, and the comparison target was enlarged to $7.5^{\circ}$. (In the spatial arrangement in Experiment 1, the exact in-between location would have been $2.9^{\circ}$ from fixation. With a stimulus size of $1.9^{\circ}$, this crowded the displays.) The standard target was presented at an eccentricity of $3.6^{\circ}$. The distance between the comparison target and the distractor was $14.4^{\circ}$, and the 
distance between the comparison and the standard targets was $7.2^{\circ}$ (Figure 1, bottom, exemplifies these conditions).

\section{Results}

The data were treated as above. One participant was not able to detect temporal order (DL $>1,000)$, and his data were not analyzed.

Figure 3 (bottom) depicts the psychometric distributions. They are very similar to those in Experiment 2. The PSSs were $-2 \mathrm{msec}$ in the unprimed condition, $39 \mathrm{msec}$ with a single prime, $32 \mathrm{msec}$ with the standard in-between the primes' locations, and again $32 \mathrm{msec}$ with the standard outside. A one-way ANOVA of PSS revealed a highly significant effect of priming $[F(3,48)=21.15, p<.0001]$. Effect size was $f=1.12$, indicating a very large effect. Planned comparisons revealed no differences between the primed conditions (all $t \mathrm{~s}<1$ ).

Perceptual latency priming (see Figure 4) was $41 \mathrm{msec}$ for a single prime and $34 \mathrm{msec}$ for the two other primed conditions.

DL did not differ with priming $(F<1)$; mean DL was $38 \mathrm{msec}$.

\section{Discussion}

In an attempt to distinguish between the predictions of the zoom lens model and the split attention hypothesis, Experiment 2 showed no evidence for attention-mediated facilitation of locations in between two attended locations: Perceptual latency priming was numerically and statistically equal if the standard target appeared at the hypothetical center of a zoom lens and if it appeared clearly outside the zoom lens.

Furthermore, facilitation was statistically equal for single primes and double primes, indicating that the observers indeed attended to both locations if a double prime was presented. Numerically, using a double prime diminished perceptual latency priming by $6 \mathrm{msec}$, but this difference did not reach significance. Note also that this small reduction of perceptual latency priming does not seem to have been due to increased difficulty of the TOJ in the double-prime conditions, in which the overall distance of the three stimuli was smallest. Increased difficulty would show up in a larger DL, which was not found in Experiment 2.

More important for the present argument, however, is the fact that the (small) reduction in both double-prime conditions is not in accordance with the zoom lens model. This model predicts a total loss or even a reversal of perceptual latency priming, but only in the in-between condition, in which the standard target appears in the center of the attended region.

An additional finding of Experiment 2 should be noted. Changing the spatial distance of the stimuli did not change the results. Mean perceptual latency priming was $37 \mathrm{msec}$ in Experiment 1 and, again, $37 \mathrm{msec}$ in Experiment 2. Thus, the distribution of attention over the visual field seems to be spatially flexible. Also, this finding is not in accord with gradient accounts of attentional distribution (e.g., Downing \& Pinker, 1985), according to which the distance between two foci should influence the amount of attention to the region between them.

\section{EXPERIMENT 3}

In the preceding experiments, the prime had the same color as the primed target. This should ameliorate metacontrast masking (see Schmidt, 2002, and Scharlau \& Ansorge, 2003, who found perfect masking of color with the stimuli used in the present experiments). However, it may also be regarded as a confounding factor: A targetcolored prime can influence the decision as to which color was presented first. Two possible mechanisms can mediate such an influence. First, the observers may have occasionally perceived the prime and reported its color. Second, the influence might be realized via sensorimotor specification of a judgment. Direct sensorimotor specification in the absence of conscious perception has been reported for speeded responses (see, e.g., Klotz \& Neumann, 1999; Kunde, Kiesel, \& Hoffmann, 2003; Neumann \& Klotz, 1994; Vorberg, Mattler, Heinecke, Schmidt, \& Schwarzbach, 2004), but it cannot be excluded that it may also be present in the motor responses by which a judgment is carried out.

Both alternative explanations can be controlled for by the same manipulation: Experiment 3 replicates Experiment 1 , with the only difference being that the prime was light gray, which was no target color and, thus, did not correspond to any of the judgment alternatives. If perceptual latency priming were to be the same as that in Experiment 1, reporting the prime's color or priming a judgment via direct specification could be ruled out.

\section{Method}

Participants. Twenty-two paid volunteers (10 females; mean age, 25 years) participated in one session of $30 \mathrm{~min}$.

Apparatus and Procedure. The apparatus and procedure did not differ from those in Experiment 1.

Stimuli. The stimuli were identical to those in Experiment 1, apart from the fact that the prime was light gray $\left(103 \mathrm{~cd} / \mathrm{m}^{2}\right)$.

\section{Results}

The data were treated as above. One participant was not able to detect temporal order (DL $>1,000)$, and his data were not analyzed.

Figure 5 (top) depicts the psychometric distributions. They are very similar to those in Experiment 1 . The PSSs were $0 \mathrm{msec}$ in the unprimed condition, $35 \mathrm{msec}$ with a single prime, $25 \mathrm{msec}$ with a double/valid prime, and $2 \mathrm{msec}$ with a double/neutral prime. A one-way ANOVA of PSS revealed a highly significant effect of priming $[F(3,69)=17.47, p<.0001]$. Effect size was $f=.9$, again indicating a large effect. Planned comparisons revealed that the double/valid condition differed from the double/neutral condition $[t(20)=3.56, p<.05]$ and from the single-prime condition $[t(20)=2.62, p<.05]$.

Perceptual latency priming (see Figure 4) was $35 \mathrm{msec}$ for a single prime and $25 \mathrm{msec}$ for a double/valid prime. 


\section{Experiment 3}

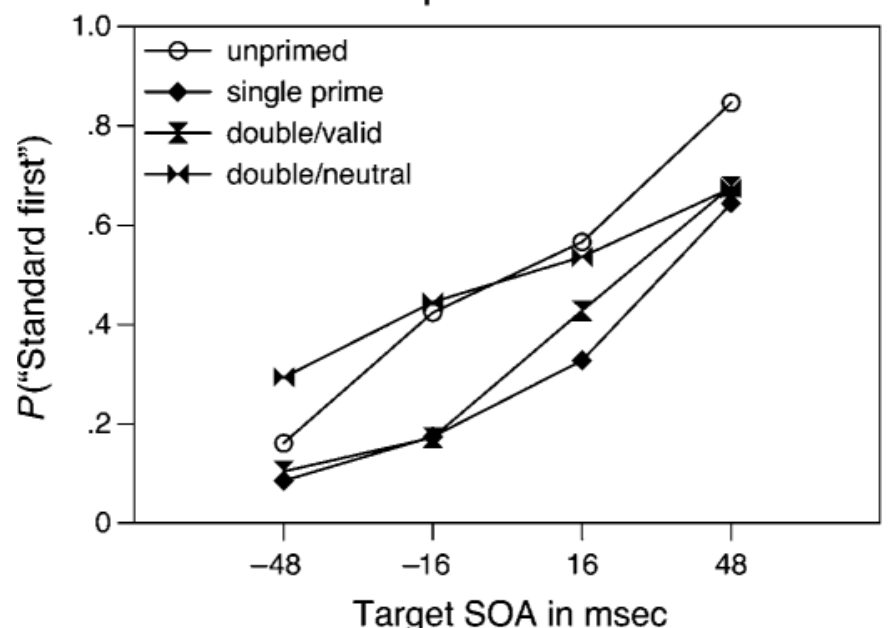

Experiment 4

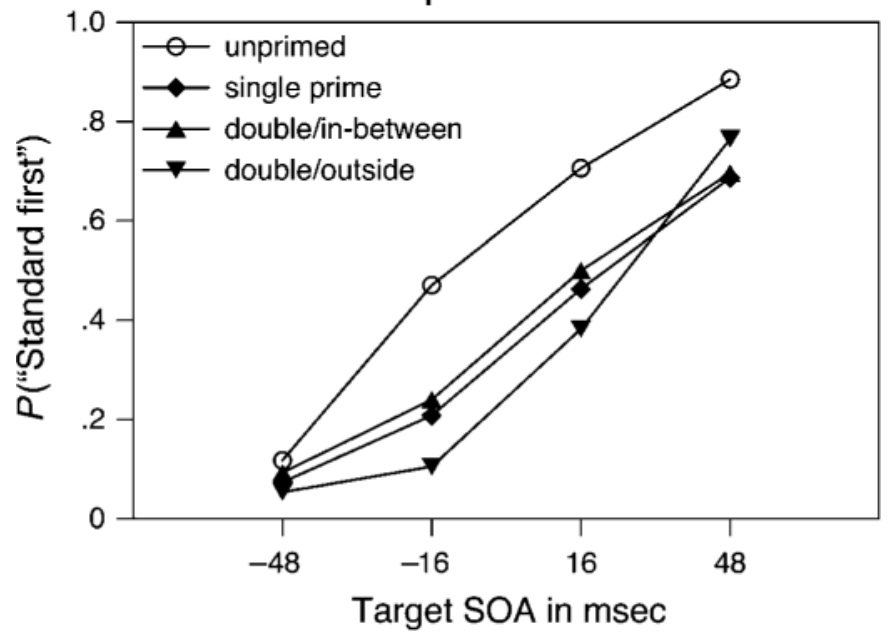

Figure 5. Psychometric distributions of the control experiments, Experiment 3 (top) and Experiment 4 (bottom).

For a double/neutral prime, no perceptual latency priming was found.

Figure 5 (top) shows that the slope of the psychometric distribution in the double/neutral condition was markedly reduced. A one-way ANOVA revealed that DL indeed differed with priming $[F(3,60)=15.03, p<.001]$. DL was $33 \mathrm{msec}$ in the unprimed condition, $37 \mathrm{msec}$ in the single-prime condition, $35 \mathrm{msec}$ with a double/valid prime, and $99 \mathrm{msec}$ with a double/neutral prime. The latter condition differed from each of the other conditions (Bonferroni comparisons, $p<.05$ ).

As a direct comparison, perceptual latency priming values for Experiments 1 and 3 were compared in a two-way ANOVA with experiment as a between-subjects factor. Only the main effect of priming was significant $[F(2,72)=$ $16.97, p<.0001]$. There was neither a main effect of experiment nor an interaction (both $F_{\mathrm{S}}<1$ ). A direct comparison of DL values across the two experiments revealed that priming also reached significance $[F(3,108)=4.26$, $p<.05]$, whereas experiment $(F<1)$ and the interaction $[F(3,108)=1.8, p=.19]$ were nonsignificant.

\section{Discussion}

The results of Experiment 3 were highly similar to those in Experiment 1, both numerically and statistically, thus ruling out the direct specification and the residual perception hypotheses. They are in line with the results of earlier studies that have demonstrated that primetarget similarity does not influence perceptual latency priming (Scharlau, 2002; Scharlau \& Neumann, 2003a). The DL results further support the attentional account: Discrimination performance was not influenced by whether the prime contained a target color or not.

Experiment 3 revealed a significantly larger DL in the double/neutral condition. In Experiment 1, DL was also numerically (although not statistically) larger in this con- 
dition. This finding might indeed support the notion of split foci: In the double/neutral condition, the observer's attention was drawn toward a location that was irrelevant for the task (the distractor's location), and attention did not cover the standard target's location. Thus, attention had to be rearranged in order to select both targets. The costs of reallocating attention might be reflected in the larger DL.

\section{EXPERIMENT 4}

The present study is concerned with a priming effect, the possible influence of a nonvisible stimulus on information processing - namely, its ability to draw attention to its location. In the preceding experiments, the prime was metacontrast masked by the trailing target. This should ensure that the observers did not judge the prime's features instead of the target's features. Experiment 3 supported this conclusion with respect to the prime's color.

However, in a different respect, masking the prime may foster a confusion of the prime and the masking targetfor example, by misbinding the respective onsets. If this confusion hypothesis holds, perceptual latency priming should be diminished if the prime is clearly visible: Unmasked primes are less likely to be confused with the targets than are masked primes.

In Experiment 4, clearly visible rectangular primes that were quite similar to the box-shaped spatial cues used in numerous cuing studies were used.

\section{Method}

Participants. Eighteen paid volunteers (12 females; mean age, 25.4 years) participated in one session of $30 \mathrm{~min}$.

Apparatus and Procedure. The apparatus and procedure did not differ from those in Experiment 2.

Stimuli. The stimuli were identical to those in Experiment 2, with only the following exception: The prime's color again was light gray, and it consisted of the four angles of a square box that surrounded the target (edge length, $3.0^{\circ}$ ).

\section{Results}

The data were treated as above. One participant was not able to detect temporal order (DL $>1,000)$, and his data were not analyzed.

Figure 5 (bottom) depicts the psychometric distributions. They were very similar to those in Experiment 2, which used the same experimental conditions. The PSSs were $-7 \mathrm{msec}$ in the unprimed condition, $24 \mathrm{msec}$ with a single prime, $25 \mathrm{msec}$ with the standard in between, and $25 \mathrm{msec}$ with the standard outside. A one-way ANOVA of PSS revealed a highly significant effect of priming $[F(3,48)=12.34, p<.001]$. Effect size was $f=.62$, again indicating a large effect. According to planned comparisons, the three primed conditions did not differ (all $t \mathrm{~s}<1$ ).

Perceptual latency priming (see Figure 4) was $31 \mathrm{msec}$ for a single prime and $32 \mathrm{msec}$ for both double primes.

The influence of priming on DL reached significance $[F(3,48)=3.39, p<.05]$. The smallest DL in the out- side condition differed from the largest DL in the inbetween condition (Bonferroni post hoc comparisons, $p<.05 ; 29$ and $36 \mathrm{msec}$ ).

As a direct comparison, perceptual latency priming values for Experiments 2 and 4 were submitted to a twoway ANOVA with experiment as a between-subjects factor. There was neither a main effect nor an interaction (all $F_{\mathrm{s}}<1$ ).

\section{Discussion}

In the present experiment, the prime was clearly visible. This means was adopted in order to ensure that the observers did not confuse the prime and the target. The results of Experiment 4 did not differ from those in Experiment 2 . These results rule out a confusion or misbinding account.

Experiment 4 showed a small influence of priming on discrimination accuracy. DL was smallest in the outside condition and largest in the in-between condition. This finding might indicate that a temporal judgment is more difficult if the stimuli are close to each other and more easy if they are separated. However, the finding that DL was equal with masked similar primes (Experiment 2) and with visible dissimilar primes (Experiment 4) does not support this conclusion, and DL typically does not vary with priming (e.g., Scharlau \& Neumann, 2003a).

\section{GENERAL DISCUSSION}

The experiments presented above support the notion that the focus of attention can be split to cover two noncontiguous regions. In the following, I will first summarize the results and link them to earlier studies on split attention. I will then consider several alternative interpretations: object-based attention, perceptual retouch, and perceptual confusion. Finally, I will dwell on the recent use of perceptual latency, or prior entry, in attention-related research.

In the present experiments, the spatial distribution of attention was assessed by perceptual latency primingthat is, the latency benefit that an attended visual stimulus achieves, as compared with a nonattended stimulus. The observers in Experiment 1 were able to attend to two nonadjacent regions or a large region without loss of facilitation for each of the regions. This was indicated by (1) the equal amount of perceptual latency priming in a condition with a single focus and a condition with double foci and (2) the lack of relative facilitation in a condition with double focus that encompassed the two to-be-compared stimuli. This finding can be integrated into a zoom lens model or the split attention hypothesis, but is not in accord with the spotlight model of attention. Experiment 2 revealed that, when two distant locations are attended, the region between them is not necessarily attended to. This finding agrees only with the notion of split attentional foci.

Experiment 3 ruled out the possibility that the observers erroneously reported the prime's color instead of the first target's color, and Experiment 4 demonstrated that percep- 
tual latency priming arises with visible and dissimilar primes, which is evidence against a misbinding or confusion account. In sum, the experiments presented above showed a robust attentional priming effect at two noncontiguous locations of the visual field. Moreover, most of the findings met a strict criterion of split attentionthat is, no influence of the second focus on the benefits achieved at the other focus.

One objection against the present results may be that in the planned comparisons, major evidence for split attention was drawn from a confirmation of the null hypothesis. However, the effect size of the priming effect investigated in the present study typically is very large ( $f>.5$ or $d>1$ ), so that the probability of a $\beta$ (Type II) error is low. Furthermore, the results of the conditions in which no effects were predicted were numerically very similar. For example, the priming effects in the double/ neutral condition of Experiments 1 and 3 were 8 and $2 \mathrm{msec}$, respectively, resulting in a mean effect of $5 \mathrm{msec}$, which is clearly marginal. The difference between double/ valid and single conditions was $8 \mathrm{msec}$ of a mean effect of more than $35 \mathrm{msec}$. In neither of the experiments did the outside and the in-between conditions differ. Also, using a double/valid prime reduced the priming effect only by $5 \mathrm{msec}$, as compared with a single-prime condition. Again, this is marginal, as compared with the mean effect of more than $35 \mathrm{msec}$. In sum, the present experiments do not completely rule out the possibility of spotlight or zoom lens mechanisms in the shifting of attention. However, the major evidence is in favor of split attentional foci.

According to Posner et al. (1980), a seemingly noncontiguous distribution of attention may be an artifact of averaging across trials with differently located, single attentional foci (e.g., Castiello \& Umiltà, 1992). For the present experiments, this explanation may be excluded on the basis of the argument made in the discussion of Experiment 1: If observers attended to only one of the primed regions, this should have diminished attentional facilitation in the double-prime, as compared with the single-prime, condition. In none of the experiments was a significant reduction found. Perceptual latency priming values were slightly smaller in the double-prime condition, but this difference did not reach significance, and even with double prime, perceptual latency priming was large and robust.

Another criterion for proving split attention is that the possible split foci must not be due to a serial, single-focus attentional scanning of the two locations. Although this possibility was not directly tested in the present study, it is unlikely. For example, studies by different authors (e.g., C. W. Eriksen \& Collins, 1969; Müller \& Findlay, 1987; Müller \& Rabbitt, 1989; Sperling \& Reeves, 1980) estimated the time needed to complete an attentional shift to be about 100-200 msec. (Of course, this estimate does not rule out the possibility that partial attentional benefits may be achieved with much smaller intervals; see, e.g., Ansorge \& Heumann, 2003.) This is well above the stimulus sequences used in the present study. The longest sequence in the present experiments was $112 \mathrm{msec}$ (64-msec priming SOA + 48-msec target SOA). Furthermore, the results accord well with those in earlier studies of split attention that also have ruled out the possibility of serial scanning (Awh \& Pashler, 2000; Hahn \& Kramer, 1998, Experiment 1).

The present findings have some further implications. Kramer and Hahn (1995; see also Hahn \& Kramer, 1998) reasoned that the failure of several studies to show evidence for split attentional foci (e.g., Heinze et al., 1994; Pan \& Eriksen, 1993) might have been due to an abruptonset presentation of distractors. Possibly, abrupt onsets, or the appearance of new objects in the visual field, may have disrupted split foci. However, in the present study, split foci were maintained although all the stimuli had sudden onsets. Thus, observers may split attention irrespective of further onsetting stimuli. Transients did not automatically or reflexively capture attention. This finding confirms those of Bichot et al. (1999), who also reported split attention in the presence of abruptly onsetting stimuli, which converges with evidence that abrupt onsets need not necessarily capture attention (e.g., Folk, Remington, \& Johnston, 1992; Folk, Remington, \& Wright, 1994; Scharlau \& Ansorge, 2003).

So far, I have been assuming that attention is focused mainly on locations in visual space (space-based attention). However, there is also evidence that attention may be directed to objects (object-based attention), rather than to locations. This evidence stems from different experimental paradigms. First, it is easier to judge two properties of the same object than to judge two properties of different objects, even if the spatial distance of the properties' locations is the same in the two conditions (Duncan, 1984). Second, it has been demonstrated that attention, if employed to a moving object, may follow this object (Driver \& Baylis, 1989; Hamm \& Klein, 2002). Third, it is difficult to ignore irrelevant information that belongs to an attended object (e.g., Baylis \& Driver, 1992; Baylis, Driver, \& McLeod, 1992). Attention thus may be allocated to noncontiguous regions if the stimuli appearing at these regions are perceptually grouped into an object (e.g., Baylis \& Driver, 1992; Kramer \& Jacobson, 1991).

However, the object-based view of attention and the space-based view are not mutually exclusive. Rather, they may be two modes of allocating attention. Most important, the object-based view does not seem a possible alternative explanation for the present results. The stimuli presented in the experiments did not meet the conditions that are usually relevant in studies on object-based attention. First, the observers always judged properties of different objects at different locations, rendering an application of Duncan's (1984) line of argumentation impossible. Second, the stimuli did not move (presupposing that no apparent motion was perceived in the displays and that attention may have followed apparent motion, as, e.g., in the study by Hamm \& Klein, 2002). Third and 
most important, the displays presented provided no strong cues for perceptual grouping: The visible stimuli were dissimilar in color and had asynchronous onsets, and although frequently they formed a regular triangle, this was not true in the double-prime conditions in Experiment 2 (altogether, $50 \%$ of the trials). By contrast, the masked double primes were similar and may have been interpreted as being the same object or as belonging to the same object. If object-based attention could explain the present results, this would, however, include the following claims. (1) Observers are able to attend to invisible objects. So far, no evidence for attention toward invisible objects has been reported, whereas space-based attention to masked information has been proven in several studies (e.g., Jaśkowski et al., 2002; Lambert, Naikar, McLachlan, \& Aitken, 1999; McCormick, 1997; Scharlau \& Neumann, 2003a). (2) Object-based attention to the masked primes persists even though later, different objects (the targets and the distractor) appear at the prime's location.

Although the present findings are very well compatible with an underlying mechanism of space-based attentional facilitation, they do not conclusively imply that only attentional facilitation can explain the present results. Response bias, perceptual confusion, or misbinding and perceptual amalgamation being ruled out, as was argued above, there are at least two alternative explanations. The perceptual retouch theory of Bachmann $(1994,1999)$, which was originally developed to account for visual backward masking, predicts perceptual latency priming as a result of the asynchrony of specific feature coding and nonspecific activation without bearing on attention. The mechanism of perceptual retouch provides for visual information's surpassing preattentive coding so that information can become consciously available. Stimulus presentation entails two coding mechanisms, cortical specific encoding of basic features and nonspecific processing via the thalamic nuclei. The latter feeds into specific representations and modulates them, providing a precondition for conscious availability. The asynchrony of the two processes, with nonspecific thalamocortical activation trailing the specific cortical processing by about 50-80 msec, explains perceptual latency priming: Because specific activation of a primed target temporally coincides with nonspecific activation that was initially triggered by the prime, the conscious representation of a primed target is established more quickly than that of an unprimed target. The present results do not suffice to distinguish between the attentional and the perceptual retouch explanations of perceptual latency priming. However, they at least provide tentative evidence against the latter account. Nonspecific activation in perceptual retouch has a low spatial resolution (Bachmann, 1994). Seemingly, this is not in accord with the present finding of split attentional foci.

A second alternative explanation of perceptual latency priming would be a variant of the amalgamation account. In the introduction, I listed findings that speak against such an explanation, such as the fact that perceptual latency priming does not change with target duration and is found for leading, although not for trailing, masked primes (which contradicts the perceptual center hypothesis) and arises even though observers can correctly date the prime's onset (which speaks against a confusion account, according to which observers are unable to separate the primetarget sequence into two events). Experiments 3 and 4 further demonstrated that confusion between the prime's color and the target's color cannot account for perceptual latency priming and that rendering the prime visible does not change the results. Although providing strong evidence against confusion, these results do not completely exclude the possibility that perceptual latency priming results from a very particular deficit in timing the onset of a second stimulus in a spatially and temporally close sequence. Settling this question requires an independent means of assessing attentional facilitation at a primed target's location-for example, by comparing discrimination accuracy or discrimination speed for primed and unprimed targets.

In the present study, I proposed using the TOJ, combined with a priming paradigm, as a novel means to look into the mechanisms of attentional control (see also Spence et al., 2001). Earlier research on prior entry and perceptual latency priming has been concerned chiefly with the question of whether this phenomenon is indeed attentional in origin - for example, by demonstrating that it is only marginally (Shore et al., 2001) or not at all (Scharlau, $2003,2004)$ influenced by response bias, or by investigating its time course, which is similar to that of other attentional benefits (Scharlau \& Neumann, 2003b). Furthermore, perceptual priming (Bar \& Biederman, 1998) is not involved in perceptual latency priming (Scharlau \& Neumann, 2003a), which again indirectly supports the attentional explanation.

The proposal to utilize perceptual latency priming for studying attention is in line with recent studies that have used prior entry or TOJs and prior entry in order to investigate various attention-related topics, such as the role of subcortical attentional processing (Zackon et al., 1999), attentional deficits in, for example, extinction (Rorden, Mattingley, Karnath, \& Driver, 1997; see also Karnath, Zimmer, \& Lewald, 2002) or unilateral neglect (Robertson, Mattingley, Rorden, \& Driver, 1998), or the processing of words of different valence depending on hemifield of presentation and mood (Enloe, Ilardi, Atchley, Cromwell, \& Sewell, 2001). A recent study directly addressed the question of attentional control. Scharlau and Ansorge (2003) used perceptual latency priming to investigate whether shifts of attention can be mediated via top-down-based control. Indeed, we found that color primes that matched the current intentions of the observers (i.e., corresponded to either of the two target colors) entailed perceptual latency priming. By contrast, primes with the color of additional distractors elicited less perceptual latency priming, the size of which did not differ significantly from zero. We interpreted this finding as support 
for top-down-modulated control of attention, as suggested by the contingent-capture hypothesis (Folk et al., 1992) or direct parameter specification (Neumann, 1990).

This finding seems to contradict the finding that featural similarity between a prime and a target is not critical for perceptual latency priming (the present Experiments 3 and 4; Scharlau \& Neumann, 2003a). Note, however, that in the earlier study, the prime's validity was $100 \%$ or, more precisely, any onset in the display marked a relevant location. This is an alternative sufficient precondition for intention-mediated capture (Yantis, 1993). By contrast, in Scharlau and Ansorge's (2003) study, there were several irrelevant distractors in the display, providing a high incentive to shift attention in correspondence with the features of the stimuli. In the present Experiments 3 and 4, one of the double primes was $100 \%$ valid and a second focus was not detrimental, thus again providing low encouragement to process the prime's features. At any rate, these results underline the fact that the perceptual latency priming paradigm can be used to investigate the mechanisms of attentional control.

In sum, the present experiments support the notion of split attentional foci by demonstrating attentional priming effects at two noncontiguous locations with little or no priming at the intervening location. The pattern of results fulfills a strict criterion of split foci-namely, that double and single foci do not differ with respect to the benefits achieved at each of the foci. Several alternative attentional interpretations are incompatible with the present findings, such as a serial scanning of the primed locations, response bias, and perceptual amalgamation. The experiments also provide evidence that TOJs and perceptual latency priming are useful means for assessing attention-mediated benefits.

\section{REFERENCES}

Ansorge, U., \& Heumann, M. (2003). Top-down contingencies in peripheral cuing: The roles of color and location. Journal of Experimental Psychology: Human Perception \& Performance, 29, 937-948.

AwH, E., \& PASHLER, H. (2000). Evidence for split attentional foci. Journal of Experimental Psychology: Human Perception \& Performance, 26, 834-846.

BACHMANN, T. (1994). Psychophysiology of visual masking: The fine structure of conscious experience. Commack, NY: Nova Science.

BaChmann, T. (1999). Twelve spatiotemporal phenomena and one explanation. In G. Aschersleben, T. Bachmann, \& J. Müsseler (Eds.), Cognitive contributions to the perception of spatial and temporal events (pp. 173-206). Amsterdam: Elsevier, North-Holland.

Bar, M., \& Biederman, I. (1998). Subliminal visual priming. Psychological Science, 9, 464-469.

BAYLIS, G. C., \& DRIVER, J. (1992). Visual parsing and response competition: The effect of grouping factors. Perception \& Psychophysics, 51, 145-162.

BAYLIS, G. C., Driver, J., \& MCLeod, P. (1992). Movement and proximity constrain miscombinations of color and form. Perception, 21, 201-218.

Bichot, N. P., CAVE, K. R., \& PAShler, H. (1999). Visual selection mediated by location: Feature-based selection of noncontiguous locations. Perception \& Psychophysics, 61, 403-423.

BreitmeYer, B. G. (1984). Visual masking: An integrative approach. Oxford: Oxford University Press.

Bridgeman, B. (1980). Temporal response characteristics of cells in monkey striate cortex measured with metacontrast masking and brightness discrimination. Brain Research, 196, 347-364.

BRoAdBENT, J. (1982). Task combination and selective intake of information. Acta Psychologica, 50, 253-290.

Castiello, U., \& Umiltà, C. (1990). Size of the attentional focus and efficiency of processing. Acta Psychologica, 73, 195-209.

Castiello, U., \& Umiltà, C. (1992). Splitting focal attention. Journal of Experimental Psychology: Human Perception \& Performance, $\underline{\mathbf{1 8}}_{\mathbf{2}}$ 837-848.

COHEN, J. (1977). Statistical power analysis for the behavioral sciences (2nd ed.). Hillsdale, NJ: Erlbaum.

Dehaene, S., Naccache, L., Le Clec'H, G., Koechlin, E., Mueller, M., Dehaene-Lambertz, G., van de Moortele, P. F., \& Le Bihan, D. (1998). Imaging unconscious semantic priming. Nature, 395, 597600.

DownING, C. J. (1988). Expectancy and visual-spatial attention: Effects on perceptual quality. Journal of Experimental Psychology: Human Perception \& Performance, 14, 188-202.

Downing, C. J., \& PinKeR, S. (1985). The spatial structure of visual attention. In M. I. Posner \& O. S. M. Marin (Eds.), Attention and performance XI: Mechanisms of attention (pp. 171-187). Hillsdale, NJ: Erlbaum.

Driver, J., \& BAYlis, G. C. (1989). Movement and visual attention: The spotlight metaphor breaks down. Journal of Experimental Psychology: Human Perception \& Performance, 15, 448-456.

DuNCAN, J. (1984). Selective attention and the organization of visual information. Journal of Experimental Psychology: General, 113, 501517.

Enloe, A. A., Ilardi, S. S., Atchley, R. A., Cromwell, R. L., \& Sewell, K. W. (2001). Word valence, attention, and hemispheric activity in depressed, remitted, and nondepressed controls. Brain \& Cognition, 46, 129-133.

ENNS, J. T., \& DI LoLlo, V. (1997). Object substitution: A new form of masking in unattended visual locations. Psychological Science, $\underline{\mathbf{8}}_{2}$ 135-139.

ERIKSEN, B. A., \& ERIKSEN, C. W. (1974). Effects of noise letters upon the identification of a target letter in a nonsearch task. Perception \& Psychophysics, 16, 143-149.

ERIKSEN, C. W., \& Collins, J. F. (1969). Visual perceptual rate under two conditions of search. Journal of Experimental Psychology, 80, 489-492.

ERIKSEN, C. W. \& Hoffman, J. E. (1972). Temporal and spatial characteristics of selective encoding from visual displays. Perception \& Psychophysics, 12, 201-204.

Eriksen, C. W., \& St. JAmES, J. D. (1986). Visual attention within and around the field of focal attention: A zoom lens model. Perception \& Psychophysics, 40, 225-240.

ERIKSEN, C. W., \& YEH, Y.-Y. (1985). Allocation of attention in the visual field. Journal of Experimental Psychology: Human Perception \& Performance, 11, 583-597.

FinneY, D. J. (1971). Probit analysis (3rd ed.). Cambridge: Cambridge University Press.

FolK, C. L., Remington, R. W., \& Johnston, J. C. (1992). Involuntary covert orienting is contingent on attentional control settings. Journal of Experimental Psychology: Human Perception \& Performance, $\underline{\mathbf{1 8}}$ 1030-1044.

FoLK, C. L., Remington, R. W., \& Wright, J. (1994). The structure of attentional control: Contingent attentional capture by apparent motion, abrupt onset, and color. Journal of Experimental Psychology: Human Perception \& Performance, 20, 317-329.

FREY, R. D. (1990). Selective attention, event perception and the criterion of acceptability principle: Evidence supporting and rejecting the doctrine of prior entry. Human Movement Science, 9, 481-530.

Hahn, S., \& Kramer, A. F. (1998). Further evidence for the division of attention among non-contiguous locations. Visual Cognition, 5, 217256.

Hamm, J. P., \& KLein, R. M. (2002). Does attention follow the motion in the "shooting line" illusion? Perception \& Psychophysics, 64, 279-291.

Handy, T. C., Kingstone, A., \& Mangun, G. R. (1996). Spatial distribution of visual attention: Perceptual sensitivity and response latency. Perception \& Psychophysics, 58, 613-627. 
HaYs, W. L. (1988). Statistics (4th ed.). Orlando, FL: Holt, Rinehart, \& Winston.

Heinze, H.-J., Luck, S. J., Münte, T. F., Gös, A., Mangun, G. R., \& Hillyard, S. A. (1994). Attention to adjacent and separate positions in space: An electrophysiological analysis. Perception \& Psychophysics, 56, 42-52.

HikosaKa, O., MiYauchi, S., \& Shimojo, S. (1993a). Focal visual attention produces illusory temporal order and motion sensation. $\underline{\mathrm{Vi}}$ sion Research, 33, 1219-1240.

HiKosAKa, O., MiYAUCHI, S., \& Shimojo, S. (1993b). Visual attention revealed by an illusion of motion. Neuroscience Research, 18, 11-18.

Hughes, H. C., \& Zimba, L. D. (1985). Spatial maps of directed visual attention. Journal of Experimental Psychology: Human Perception \& Performance, 11, 409-430.

JAŚKOWSKI, P. (1993). Selective attention and temporal-order judgment. Perception, 22, 681-689.

JAŚKOWSKI, P., VAN DER LUBbe, R. H. J., SchlotTerbeck, E., \& VerLEGER, R. (2002). Traces left on visual selective attention by stimuli that are not consciously identified. Psychological Science, 13, 48-54.

KARNATH, H.-O., ZimMER, U., \& LeWALD, J. (2002). Impaired perception of temporal order in auditory extinction. Neuropsychologia, $\underline{\mathbf{4 0}}$, 1977-1982.

KLOTZ, W., \& Neumann, O. (1999). Motor activation without conscious discrimination in metacontrast masking. Journal of Experimental Psychology: Human Perception \& Performance, 25, 976-992.

KRAMER, A. F., \& HAHN, S. (1995). Splitting the beam: Distribution of attention over noncontiguous regions of the visual field. Psychological Science, 6, 381-386.

KRAMER, A. F., $\overline{\text { J JACOBSON }}$ A. (1991). Perceptual organization and focused attention. In M. Kubovy \& J. R. Pomerantz (Eds.), Perceptual organization (pp. 181-211). Hillsdale, NJ: Erlbaum.

Kunde, W., Kiesel, A., \& Hoffmann, J. (2003). Conscious control over the content of unconscious cognition. Cognition, 88, 223-242.

LaBerge, D. (1983). Spatial extent of attention to letters and words. Journal of Experimental Psychology: Human Perception \& Performance, 9, 371-379.

LABERGE, D., \& BROWN, V. (1989). Theory of attentional operations in shape identification. Psychological Review, 96, 101-124.

Lambert, A., Naikar, N., McLachlan, K., \& AitKen, V. (1999). A new component of visual orienting: Implicit effects of peripheral information and subthreshold cues on covert attention. Journal of Experimental Psychology: Human Perception \& Performance, 25, 321340 .

LEUTHOLD, H., \& KopP, B. (1998). Mechanisms of priming by masked stimuli: Inferences from event-related brain potentials. Psychological Science, 9, 263-269.

MCCORMICK, P. A. (1997). Orienting attention without awareness. Journal of Experimental Psychology: Human Perception \& Performance, 23, 168-180.

MCCORMICK, P. A., \& KLEIN, R. (1990). The spatial distribution of attention during covert visual orienting. Acta Psychologica, 75, 225-242.

Müller, H. J., \& Findlay, J. M. (1987). Sensitivity and criterion effects in the spatial cuing of visual attention. Perception \& Psychophysics, 42, 383-399.

MÜLLER, H. J., \& RABBITt, P. M. A. (1989). Reflexive and voluntary orienting of visual attention: Time course of activation and resistance to interruption. Journal of Experimental Psychology: Human Perception \& Performance, 15, 315-330.

NAKAYAMA, K., \& MACKEBEN, M. (1989). Sustained and transient components of focal visual attention. Vision Research, 29, 1631-1647.

Neumann, O. (1990). Direct parameter specification and the concept of perception. Psychological Research/Psychologische Forschung, 52, 207-215.

Neumann, O., Esselmann, U., \& Klotz, W. (1993). Differential effects of visual-spatial attention on response latency and temporalorder judgment. Psychological Research, 56, 26-34.

NeumanN, O., \& KLOTZ, W. (1994). Motor responses to nonreportable, masked stimuli: Where is the limit of direct parameter specification? In C. Umiltà \& M. Moscovitch (Eds.), Attention and performance $X V$ : Conscious and nonconscious information processing (pp. 123150). Cambridge, MA: MIT Press.
PAN, K., \& ERIKSEN, C. W. (1993). Attentional distribution in the visual field during same-different judgments as assessed by response competition. Perception \& Psychophysics, 53, 134-144.

PosNer, M. I. (1980). Orienting of attention. Quarterly Journal of Experimental Psychology, 32, 3-25.

Posner, M. I., SNYDER, C. R. R., \& Davidson, B. J. (1980). Attention and the detection of signals. Journal of Experimental Psychology: General, 109, 160-174.

Robertson, I. H., MATtingley, J. B., RoRden, C., \& Driver, J. (1998). Phasic alerting of neglect patients overcomes their spatial deficit in visual awareness. Nature, 395, 169-172.

Rorden, C., Mattingley, J. B., Karnath, H.-O., \& Driver, J. (1997). Visual extinction and prior entry: Impaired perception of temporal order with intact motion perception after unilateral parietal damage. Neuropsychologia, 35, 421-433.

SCHARLAU, I. (2002). Leading, but not trailing, primes influence temporal order perception: Further evidence for an attentional account of perceptual latency priming. Perception \& Psychophysics, 64, 13461360 .

SCHARLAU, I. (2003). Novel methods for assessing attentional facilitation and prior entry. Manuscript submitted for publication.

SCHARLAU, I. (2004). Evidence against response bias in temporal order tasks with attention manipulation by masked primes. Psychological Research, 68, 224-236.

SCHARLAU, I., \& ANSORGE, U. (2003). Direct parameter specification of an attention shift: Evidence from perceptual latency priming. Vision Research, 43, 1352-1363.

Scharlau, I., \& NeumanN, O. (2003a). Perceptual latency priming by metacontrast-masked stimuli: Evidence for an attentional interpretation. Psychological Research, 67, 184-197.

SCHARLAU, I., \& NEUMANN, O. (2003b). Temporal parameters and time course of perceptual latency priming. Acta Psychologica, 113, 185-203.

Schiller, P. H., \& SMITH, M. C. (1966). Detection in metacontrast. Journal of Experimental Psychology, 71, 32-39.

ScHMIDT, T. (2002). The finger in flight: Real-time motor control by visually masked color stimuli. Psychological Science, 13, 112-117.

Scotт, S. K. (1998). The point of P-centres. Psychological Research, 61, 4-11.

SHORE, D. I., SPence, C., \& KLeIN, R. M. (2001). Visual prior entry. Psychological Science, 12, 205-212.

Shulman, G. L., Remington, R., \& McLean, J. P. (1979). Moving attention through visual space. Journal of Experimental Psychology: Human Perception \& Performance, 5, 522-526.

SpEnce, C., Shore, D. I., \& KLEIN, R. M. (2001). Multisensory prior entry. Journal of Experimental Psychology: General, 130, 799-832.

Sperling, G., \& ReEves, A. (1980). Measuring the reaction time of an unobservable response: A shift of visual attention. In R. Nickerson (Ed.), Attention and performance VIII (pp. 347-360). Hillsdale, NJ: Erlbaum.

Steglich, C., \& Neumann, O. (2000). Temporal, but not spatial, context modulates a masked prime's effect on temporal order judgment, but not on response latency. Psychological Research, 63, 36-47.

Stelmach, L. B., Campsall, J. M., \& Herdman, C. M. (1997). Attentional and ocular movements. Journal of Experimental Psychology: Human Perception \& Performance, 23, 823-844.

StelmaCh, L. B., \& Herdman, C. M. (1991). Directed attention and perception of temporal order. Journal of Experimental Psychology: Human Perception \& Performance, 17, 539-550.

TiTCHENER, E. M. (1908). Lectures on the elementary psychology of feeling and attention. New York: Macmillan.

Treisman, A. M. (1988). Features and objects: The Fourteenth Bartlett Memorial Lecture. Quarterly Journal of Experimental Psychology, 40A, 201-237.

TsAL, Y. (1983). Movements of attention across the visual field. Journal of Experimental Psychology: Human Perception \& Performance, 9, 523-530.

Túnatto, M., Benso, F., Facoetti, A., Galfano, G., Mascetti, G. G., \& UMiltà, C. (2000). Automatic and voluntary focusing of attention. Perception \& Psychophysics, 62, 935-952.

Vorberg, D., Mattler, U., Heinecke, A., Schmidt, T., \& Schwarz$\mathrm{BACH}$, J. (2004). Invariant time-course of priming with and without 
awareness. In C. Kaernbach, E. Schröger, \& H. J. Müller (Eds.), Psychophysics beyond sensation: Laws and invariants of human cognition (pp. 271-289). Hillsdale, NJ: Erlbaum.

Werner, H. (1935). Studies on contour: I. Qualitative analyses. American Journal of Psychology, 47, 40-64.

Wiggs, C. L., \& MARTIN, A. (1998). Properties and mechanisms of perceptual priming. Current Opinion in Neurobiology, 8, 227-233.

YANTIS, S. (1993). Stimulus-driven attentional capture and attentional control settings. Journal of Experimental Psychology: Human Perception \& Performance, 19, 676-681.

Zackon, D. H., Casson, E. J., Zafar, A., Stelmach, L., \& Racette, L. (1999). The temporal order judgment paradigm: Subcortical attentional contribution under exogenous and endogenous cueing conditions. Neuropsychologia, 37, 511-520.

\section{NOTES}

1. Metacontrast masking is a variant of visual backward masking. A stimulus is trailed by a laterally adjoining stimulus - for example, a disk by a surrounding ring. Under appropriate temporal conditions, metacon- trast masking leads to phenomenal disappearance of the first stimulus. Its brightness is reduced (e.g., Bridgeman, 1980), perception of its contours is impaired (e.g., Werner, 1935), features such as color (e.g., Schmidt, 2002) or shape (e.g., Klotz \& Neumann, 1999) cannot be discriminated, and detection errors increase (e.g., Scharlau \& Neumann, 2003a; Schiller $\&$ Smith, 1966). Metacontrast masking is strongest with intermediate onset asynchronies of the stimuli of approximately 40-80 msec (Bachmann, 1994; Breitmeyer, 1984; Enns \& Di Lollo, 1997).

2. Attentional priming thus is a further influence that a masked visual stimulus (a prime) may have on information processing, besides, for example, sensorimotor priming of response preparation and execution (e.g., Leuthold \& Kopp, 1998; Neumann \& Klotz, 1994; Vorberg, Mattler, Heinecke, Schmidt, \& Schwarzbach, 2004), perceptual priming of feature discrimination (Bar \& Biederman, 1998; Wiggs \& Martin, 1998), or semantic priming (Dehaene et al., 1998).

(Manuscript received February 20, 2003; revision accepted for publication October 15, 2003.) 